Article

\title{
Enhancing the Drag Reduction Phenomenon within a Rotating Disk Apparatus Using Polymer-Surfactant Additives
}

\author{
Musaab K. Rashed 1,2, Mohamad Amran Mohd Salleh ${ }^{1,3, *}$, Hayder A. Abdulbari ${ }^{4}$ and \\ Mohd Halim Shah Ismail ${ }^{1}$ \\ 1 Department of Chemical and Environmental Engineering, Faculty of Engineering, Universiti Putra Malaysia, \\ 43300 UPM Serdang, Selangor, Malaysia; ymkr2016@gmail.com (M.K.R.); mshalim@upm.edu.my (M.H.S.I.) \\ 2 Institute of Technology, Middle Technical University, Foundation of Technical Education, \\ Baghdad-Alzafaranya, P.O. Box 29008, Iraq \\ 3 Material and Processing Technology Laboratory, Institute of Advanced Technology, \\ Universiti Putra Malaysia, 43300 UPM Serdang, Selangor, Malaysia \\ 4 Center of Excellence for Advanced Research in Fluid Flow, Universiti Malaysia Pahang, Gambang, \\ 26300 Kuantan, Pahang, Malaysia; hayder.bari@gmail.com \\ * Correspondence: asalleh@upm.edu.my; Tel.: +60-193-564-475
}

Academic Editor: Serafim Kalliadasis

Received: 21 August 2016; Accepted: 9 November 2016; Published: 6 December 2016

\begin{abstract}
Pipelines and tubes play important roles in transporting economic liquids, such as water, petroleum derivatives, and crude oil. However, turbulence reduces the initial flow rate at which liquids are pumped, thereby making liquid transportation through pipelines inefficient. This study focuses on enhancing the drag reduction (DR) phenomenon within a rotating disk apparatus (RDA) using polymer-surfactant additives. The complex mixture of polyisobutylene (PIB) and sodium dioctyl sulfosuccinate (SDS) was used. These materials were tested individually and as a complex mixture in RDA at various concentrations and rotational speeds (rpm). The morphology of this complex was investigated using transmission electronic microscopy (TEM). The reduction of the degradation level caused by the continuous circulation of surfactant additives in RDA could improve the long-term DR level. Experimental result shows that the maximum \%DR of the complex mixture was $21.455 \%$ at $3000 \mathrm{rpm}$, while the PIB and SDS were $19.197 \%$ and $8.03 \%$, respectively. Therefore, the complex mixture had better performance than these substances alone and were highly dependent on the alkyl chain of the surfactant.
\end{abstract}

Keywords: polymer; surfactants; drag reduction; complex mixtures; rotating disk apparatus (RDA)

\section{Introduction}

Transportation of liquids in pipelines and in the petroleum industries requires a high percentage of energy consumption. In several cases, energy is dissipated because fluids are conveyed at high turbulent flow, thereby resulting in frictional resistance called drag. In other cases, pumps should be used at strategic pumping stations to maintain the flow of these liquids. In view of these circumstances, measures are necessary to reduce energy dissipation, turbulence in the pipeline, and maintain the flow rate. Notable among these approaches is the use of polymeric additives, surfactants, fibers, and other drag reducing agents (DRAs).

The frictional drag forces of fluids under turbulent flow conditions can be decreased significantly by adding a minute quantity of drag-reducing additives, such as polymers or surfactants. This approach is the most commonly applied technique to reduce the turbulent friction between a solid surface and fluid [1]. A maximum drag reduction (DR) percentage of approximately $80 \%$ in the pipe flow 
and approximately $50 \%$ in the rotating disk apparatus (RDA) can be easily obtained [2]. Different types of synthetic and natural polymers were initially used as drag-reducing additives for turbulent flow. Among these polymers are polyethylene oxide (PEO) [3-7], polyacrylamide (PAAM) [8-10], polyisobutylene (PIB) [11-14], xanthan gum [15-17], and guar gum [18,19], among others. However, most of these polymers in the solution are often influenced by mechanical degradation, which reduces their short-term DR effectiveness $[19,20]$. Other materials that have the capability to withstand mechanical degradation by the formation of micelles have been explored as well. These materials are called surfactants and research has been conducted on these materials to investigate their DR ability [21-23]. However, surfactants are less effective than polymers [24]; thus, alternative solutions are necessary. Therefore, different surfactants are combined with these polymers to improve the latter's DR effectiveness and mechanical degradation resistance. The properties of solutions containing polymer and surfactant have been explained by assuming the formation of a polymer-surfactant complex resulting from the binding of the surfactant ions onto the polymer chain. These complex properties are extremely different than the properties of their individual materials, and rheological properties of solutions appear to have changed [25]. The interactions between polymers and surfactants have technical and fundamental importance and is extensively used in different applications, such as petroleum industry, pharmaceutical, and personal care products [26,27]. Several parameters, such as polymer hydrophobicity, charge density, surfactant head group structure, ionic strength, and flexibility, are affected by the binding between the surfactants and polymers [28]. In synthetic polymer-surfactant systems, polyelectrolytes and oppositely charged surfactants produce the strongest combination [29].

Different complex mixtures have been used recently as DRAs in pipelines $[24,30,31]$ and rotating disk apparatus [32-35]. Mohsenipour et al. [24] studied the interaction between an anionic copolymer, which comprises acrylamide and sodium acrylate (referred to as PAM) and cationic surfactant of octadecyltrimethylammonium chloride (OTAC), in pipeline flow. Deionized and tap water were used to prepare the complex solutions. The aforementioned authors observed that the polymer properties were significantly affected by surfactant addition, where the DR efficiency of PAM was decreased with the addition of OTAC. However, the influence of OTAC on the DR performance was considerably pronounced at low concentrations of PAM. Kim et al. [34] analyzed the complex mixture of polyacrylicacid (PAA) and sodium dodecyl sulfate (SDS) as DRA under turbulent flow in a rotating disk apparatus. They concluded that the polymer chain dimension was increased by the addition of SDS and the $\mathrm{pH}$ effect, thereby improving the DR efficiency. In addition, the DR efficiency increased with the complex concentration until the critical concentration; above this concentration, the DR efficiency decreased more rapidly than that of the pure polymer solution. Although research on the complex mixture of polymer with surfactants' additives in pipelines has been conducted, this feature and the stability and DR characteristics for RDA have not been analyzed at high ranges of the Reynolds number.

This study analyzes the complex mixture formation of polyisobutylene (PIB) (cationic polymer) and SDS (anionic surfactant). These additives were selected because of their ability to completely dissolve in diesel fuel and to integrate with one another and interact physically because of the difference in their charge, which supports their attraction. DR behaviors of PIB, SDS, and their mixtures in diesel fuel solution were compared in an enclosed RDA. The morphology of this complex mixture was investigated through transmission electronic microscopy (TEM). In addition, the influence of different variables on $\% \mathrm{DR}$, such as complex concentration and rotational disk speed, was studied.

\section{Materials and Methods}

\subsection{Materials}

PIB with a high molecular weight of $4.7 \times 10^{6} \mathrm{~g} / \mathrm{mol}$ and SDS with a molecular weight of $444.55 \mathrm{~g} / \mathrm{mol}$ were purchased from Sigma Aldrich (Semenyih, Selangor, Malaysia) and used in this study without further purification. The complex mixture of these two materials was prepared 
by dissolving a specific weight of PIB in $4.5 \mathrm{~L}$ of diesel fuel, which was procured from Shell, Gambang-Kuantan Road, Pahang, Malaysia. The surfactant was directly added into this solution to obtain the appropriate concentration of mixture solutions. Different complex concentrations were prepared using five concentrations of polymer (i.e., 50, 100, 150, 200, and $300 \mathrm{ppm}$ ) and surfactant (i.e., 200, 400, 600, 800, and 1000 ppm). The procedure adopted by Bari et al. [35] was followed in the current study.

\subsection{Apparatus Description}

This study used an RDA to simulate external flow. The schematic representation of this setup is shown in Figure 1. This instrument mainly comprises a stainless steel cylindrical fluid container and $2 \mathrm{~cm}$-thick stainless steel lid to seal the solution. The diameter and height of the stainless steel cylinder are 18 and $11 \mathrm{~cm}$, respectively. The distance between the disk surface and fluid container lid is $10 \mathrm{~mm}$, and such distant is constant for all disk types. At the center of the lid is a $22 \mathrm{~mm}$ diameter circle that enables the entry of a $1.9 \mathrm{~cm}$ diameter rotating shaft. This part is supported by two bearings to avoid vibration at high rotational speeds. An aluminum rotary disk with $0.6 \mathrm{~cm}$ thickness and $14 \mathrm{~cm}$ diameter is connected to one side of the shaft. On the other side of the shaft is an electric servo motor (XINJE, AC SERVO MOTOR, MS-80STE-M02430B-20P7, Wuxi Xinje electric Co., Ltd., Wuxi, China.) that enables the disk to be rotated with different rotational speed values from 0 to $3000 \mathrm{rpm}$. The drive motor is supported by a cast iron frame, which ensures the accurate positioning of the motor. The volume of solution required to fill the container is approximately $4.2 \mathrm{~L}$. RDA is connected to a computer display system for data collection, recording, and control of the rotational disk speed. The loaded torque on the disk is measured using a highly precise torque sensor (LONGLV-WTQ1050D, Shanghai Long Journey Electronics Technology Co., Ltd., Shanghai, China) Range: 3 Nm, Output: $1.397 \mathrm{mV} / \mathrm{V}$ ). The torque values are transformed to readable form in the computer display system using the InduSoft Web Studio v7.1 software, by an Invensys company, London, UK, 2013. A temperature sensor (screw in thermocouple type-T) is used to measure the solution temperature during the operation process and is observed from the computer display system. An electric motor with a spiral thread shift is used to make the disk changing process easy by moving the disk holding shift up to change the disk and later move it down until the desired level of testing. For all experiments, the system temperature was maintained at $27 \pm 0.05^{\circ} \mathrm{C}$. When essential torques, that is, $T_{\mathrm{s}}$ and $T_{\mathrm{c}}$, rotate the disk in the pure solvent and the complex mixture solution, respectively, the percent DR can be determined from the following formula:

$$
\% D R=\frac{T_{\mathrm{s}}-T_{\mathrm{c}}}{T_{\mathrm{s}}} \times 100 \%
$$

The rotational Reynolds number is calculated as follows:

$$
R e=\frac{\rho \omega r^{2}}{\mu}
$$

where $\rho$ is the fluid density, $\mu$ is the fluid viscosity, and $r$ is the radius of the disk. The critical Reynolds number shows that the flow transfer from laminar to turbulent is $3 \times 10^{5}[4,19,36,37]$. 


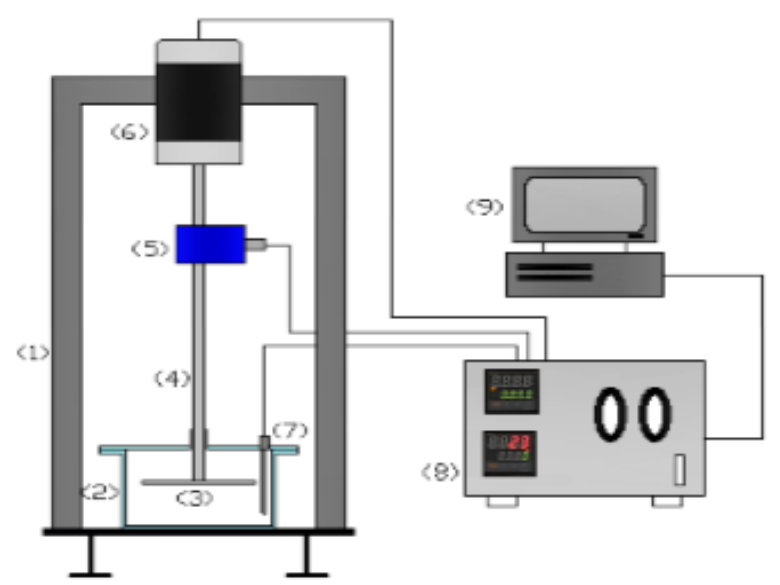

Figure 1. Schematic diagram of rotating disk apparatus (RDA). Legend: (1) Outside frame, (2) fluid container, (3) rotating disk, (4) disk holding shift, (5) torque sensor, (6) electric motor, (7) thermocouple, (8) controller interface, and (9) PC.

\subsection{TEM}

The morphology of the optimum mixture concentration at which the maximum DR was achieved was investigated using TEM. INSTITUT BIOSAINS (IBS), University Putra Malaysia provided the service using a Hitachi H-7100 model, Rescience Inc. Co., Ltd., Seoul, Korea.

\section{Results and Discussion}

Figure 2a depicts the effects of the PIB concentration on the DR performance as a function of disk rotational speed. By contrast, Figure $2 b$ shows the effect of Reynolds number on \%DR with different polymer concentrations. The rotational speed of the disk varied from $2000 \mathrm{rpm}$ at 100 intervals to approximately $3000 \mathrm{rpm}$, which corresponding to a Re of 302,227 to 453,341. From the Figure 2a, the DR percentage of the additive is favored by the polymer concentration. The \%DR increased for the 50 and $100 \mathrm{ppm}$ of the sample. However, DR decreased with $150 \mathrm{ppm}$. The decrease was considerably pronounced at rotational speeds ranging from 2000 to $2200 \mathrm{rpm}$. Such a point could be the critical concentration point of this polymer. Similar observations have been reported by Kim et al. $[3,19,36]$. The authors concluded that the two competitive mechanisms or effects relate to the polymer concentration on \%DR. They also suggested that the percentage DR could increase with increasing concentration because of the increased number of drag reducers available. Nevertheless, further increasing the polymer concentration leads to a drastic increase in the eddy viscosity, and the degree of turbulence decreases (i.e., increase in frictional drag and reduction of $R e$ ). In addition, \%DR increased with the rotational speed, as evidently shown in Figure $2 b$. By increasing the rotational speed (i.e., increasing the $R e$ ), the degree of turbulence above the disk surface will increase. This feature will provide a considerably suitable environment for the polymer molecules to perform. Consequently, the additive interaction with turbulent structures formed inside RDA could be controlled. Hence, numerous polymer molecules interfere within the turbulent structures, suppress the formation of eddies on the disk surface, thereby increasing \%DR. This study obtained approximately $19.197 \%$ DR at $150 \mathrm{ppm}$ of PIB and $3000 \mathrm{rpm}(\operatorname{Re}=453,341)$. 

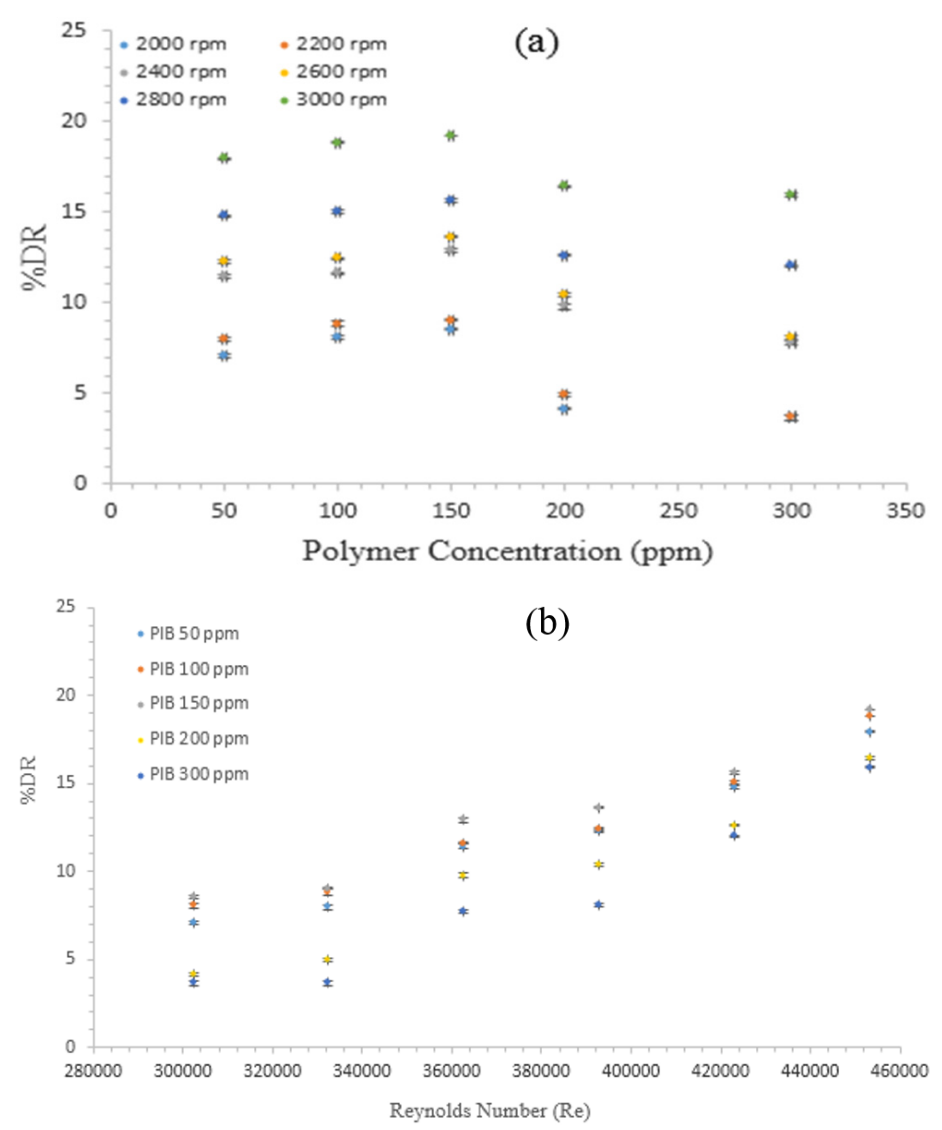

Figure 2. Effects of (a) Polyisobutylene (PIB) concentrations; and (b) Re on drag reduction percentage $(\% \mathrm{DR})$ of diesel fuel with polymer additives.

Figure 3a depicts the effects of the SDS concentration on \%DR as a function of rotational velocity, while Figure $3 \mathrm{~b}$ shows the effect of the Re on \%DR with different surfactant concentrations. Evidently, $\%$ DR increased with the SDS concentration because surfactant working mechanism could be based on the increase in drag reducer molecules, which is favored by the increase in their respective concentrations. Apart from such observation, \%DR evidently increased with the rotational speed. This quality could be attributed to the capability of the surfactant to self-repair (micelles formation) and return to its original form after passing through the high shear stress regions. The average distance between micelles is substantially small and difficult to break by strong turbulence eddies and shear stress. In addition, no DR was observed at $200 \mathrm{ppm}$ for all rotational speeds except at $3000 \mathrm{rpm}$, where $\% \mathrm{DR}$ was approximately $1.5 \%$. The negative $\mathrm{DR}$ is due to the relation between the degree of turbulence and the DR effect of the polymer or surfactant additives. DR occurs when an external or additional effect (additives) acting within the flow media will change the flow behavior and degree of turbulence in a manner that can reduce power dissipation. Such activity happens when the external effect balances overcome the internal effect (turbulence). In many cases, the DR technique fails to act because this balancing effect is not reached, although the degree of turbulence in many cases plays a significant role in controlling the DR performance. Hence, the negative readings were observed in cases where the surfactant concentration was unsuitable to suppress turbulence and started to show negative performance by creating considerable turbulent and resistive motion. The highest \%DR achieved by using SDS was approximately $8.03 \%$ at concentrations of $1000 \mathrm{ppm}$ and angular velocity of $3000 \mathrm{rpm}$. From Figures 2 and 3, we can conclude that both PIB and SDS were able to reduce drag; however, DR of PIB is more pronounced than that of SDS. This outcome could be the result of the viscoelastic nature of the polymer, which is limited with the surfactant. 

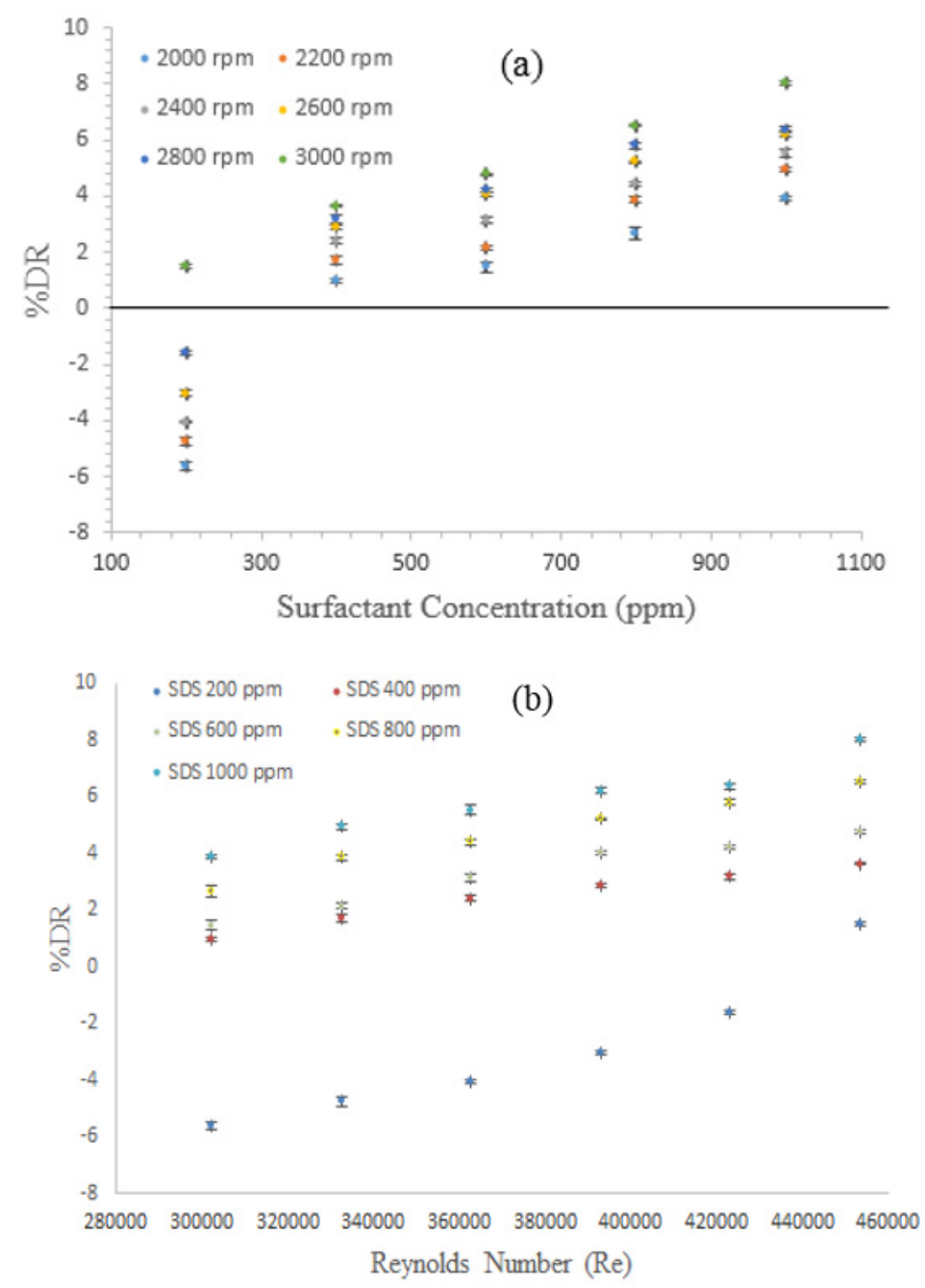

Figure 3. Effects of (a) sodium dioctyl sulfosuccinate (SDS) concentrations; and (b) Re on \%DR of diesel fuel with surfactant additive.

Figure 4a shows the effects of five different complexes prepared from PIB and SDS at various concentrations, while Figure $4 \mathrm{~b}$ depicts the effect of the Re on $\% \mathrm{DR}$ as a function of the different complex concentrations. This study investigates the DR performance of the complexes with respect to various rotational speeds of the disk. The result indicates that all the complexes investigated showed increases in DR with corresponding increase in the rpm. Such increase in rpm is the same with the increase in torque. From the Figure 4a,b, the complex mixture of PIB $150+$ Di-Octyl 1000 showed the best result and was followed by the complex mixture of PIB $100+$ Di-Octyl 1000. At the commencement of the experiment, all the concentrations tested followed a regular pattern. This quality was illustrated by the increase in the DR, which could be attributed to the polymer concentration. Polymers are more effective than the surfactants and complexes in certain occasions [38].

As Re increased to approximately 332,450, DR of all investigated complexes registered a corresponding increase. However, at a Re above 392,896, the surfactants started to gain momentum for the formation of micelles and reached the CMC (critical micelles concentration) point. At this point, the surfactants contributed to the DR efficiency of the polymer, thereby contributing to the entire process. Hence, the surfactant CMC responded to the change of environmental condition that affected the entire complex mixture [39]. However, when the situation realigns and re-enacts the DR attribute, DR reached its peak at approximately $R e=453,341$. Similar observations were reported in [38], where DR complexes were observed to be influenced by the surfactant re-micellization. 

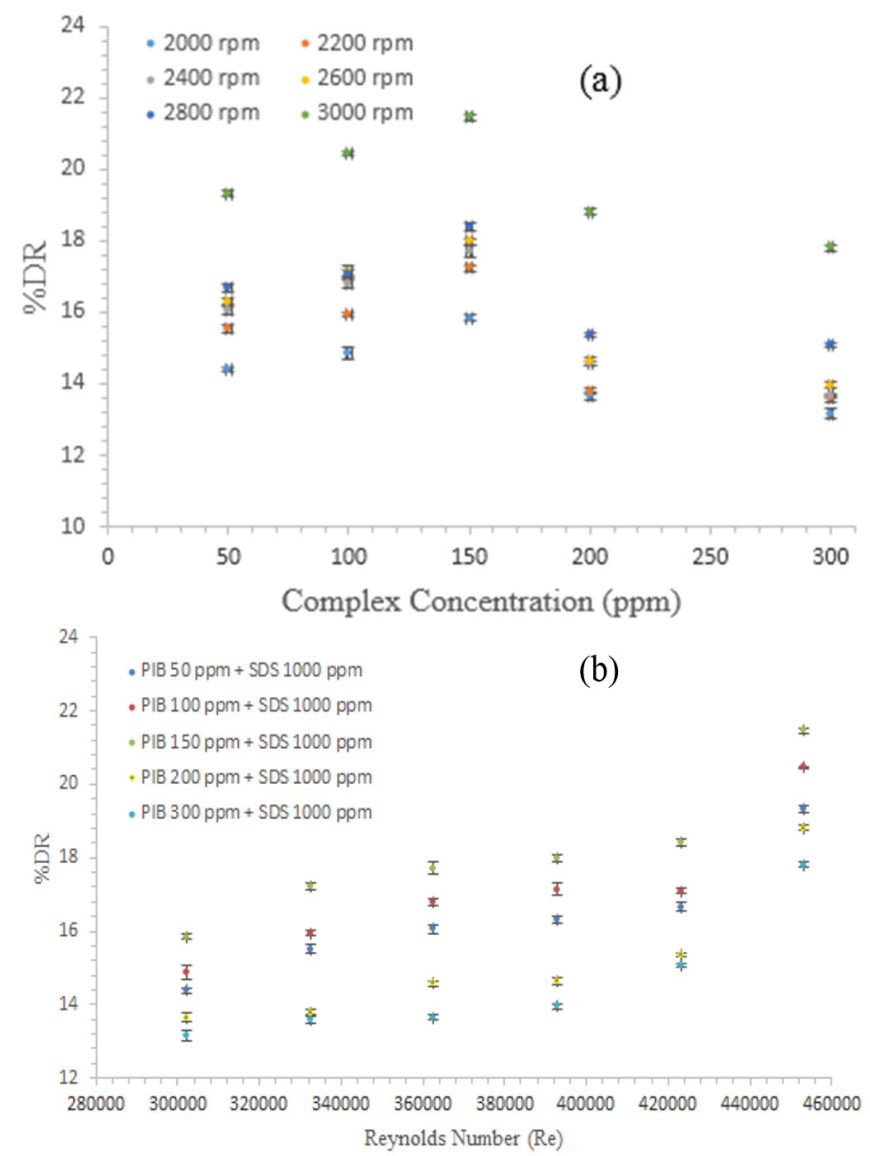

Figure 4. Effects of (a) complex mixture concentrations (five PIB concentration + 1000 ppm SDS) and (b) $\operatorname{Re}$ on $\% \mathrm{DR}$ of diesel fuel with complex additives.

Figure 5a shows a comparative study of various best additives that were investigated while considering their torque with respect to Re. Overall, all materials showed torque increase with the corresponding $R e$ increase. From the data obtained in the present study, the best performance in this respect was obtained for the complex mixture of PIB $150+$ SDS 1000 ppm. Next was PIB at 150 ppm and the least DR was only obtained for the SDS at $1000 \mathrm{ppm}$ despite the high concentration of SDS at approximately $1000 \mathrm{ppm}$. PIB of only $150 \mathrm{ppm}$ was observed to show a better performance than SDS. This observation further confirms initial observations and conclusions that the DR efficiency of polymers is greater than that of the surfactants [38].

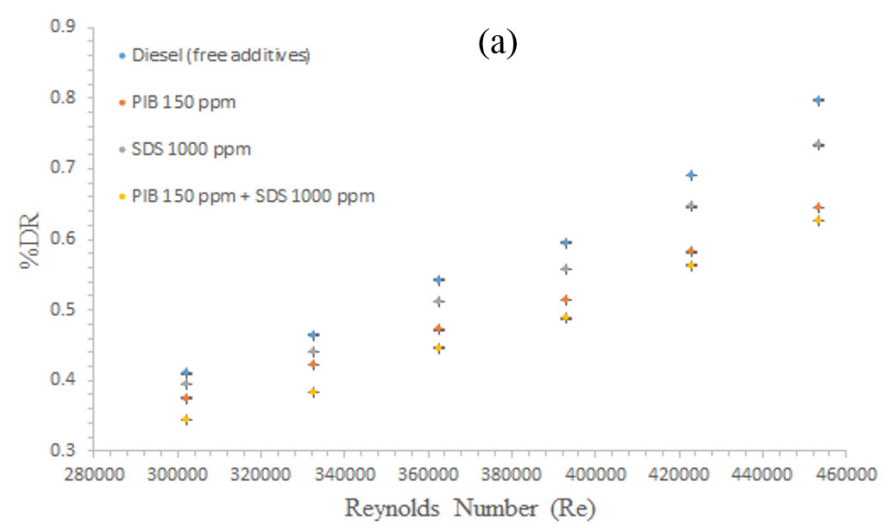

Figure 5. Cont. 


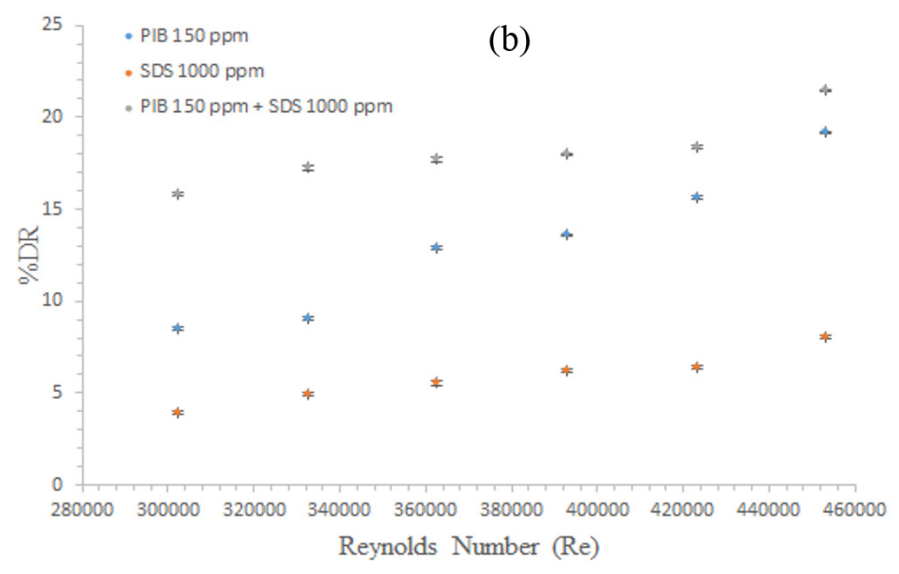

Figure 5. Comparison of (a) torque; and (b) DR performance for polymer, surfactant, and their complex with different concentrations using smooth disk.

In addition, the complex mixture formed from the combination of any two or more additives performs better than the individual parties. A similar observation was made in $[24,29,30]$. This performance was expected because of the successful interaction between the surfactant micelles and polymers chains that formed a viscoelastic polymer-surfactant complex. This complex can interfere with the turbulence structures in the main flow (eddies) and can suppress an extensive spectrum of these eddies because of the modified properties gained by forming such a complex. Thus, this result confirms that the contributory action and synergistic act of these additives have a major role to play in the complex mixture.

Similarly, investigating the effects of the DR percentage against Re for various additives is depicted in Figure 5b. From the observation, all the materials investigated reduced drag. Apart from this observation, all their DR efficacy increased with the corresponding Re increase. However, the best performance was observed with the complex mixture.

From Figure 5b, PIB at 150 ppm and SDS at 1000 ppm showed a linear trend. Apart from this quality, they both increased DR as Re increased. However, their performances were not the same. This figure shows that the polymer exhibited an improved DR with an initial value of $8.78 \%$ at $R e=302,227$ to a maximum value of 19.197 at $R e=453,341$. For the surfactant, SDS at $1000 \mathrm{ppm}$ was less efficient compared to the polymer. For the surfactant, even at $1000 \mathrm{ppm}$, DR with an initial DR of 3.9 at $R e=302,227$ to a maximum value of 8.03 at $R e=453,341$. This behavior further confirms the initial observation that the surfactants are less effective than the polymers. Lastly, observing the complex mixture of the duo gave a direct trend, although DR increased as Re increased. However, various observations were made in the trend as well.

From the commencement of the experiment at approximately $\operatorname{Re}$ of 302,227 to 362,673 , an initial increase in the DR effect with the Re was observed. However, the DR values were observed to be the same at approximately $R e$ of 362,673 to 392,896 . At this point, the materials have not been completely stretched to make any reasonable effect. However, DR at approximately $R e=423,118$ continuously increased from a value of 18.17 to 21.455 until the end of the experiment. Hence, the complex has been completely stretched and the synergistic action of the two additives is best felt at this point.

The stander error and stander deviation were calculated by repeated the all runs for five times and the average value of torque and \%DR were considered. Their values were tabulated in Tables S1-S9, which are available online at www.mdpi.com/2076-3417/6/12/355/s1.

Figure 6 shows the complete interaction as a result of TEM, where the aggregate is formed by the surrounding polymer chain (small disc) to the threadlike micelles of the surfactant (large disc) Similar observations were made in [40], while working with a complex mixture of polyacrylamide (PAM) and sodium dodecyl benzene sulfonate (SDBS) in an RDA. 


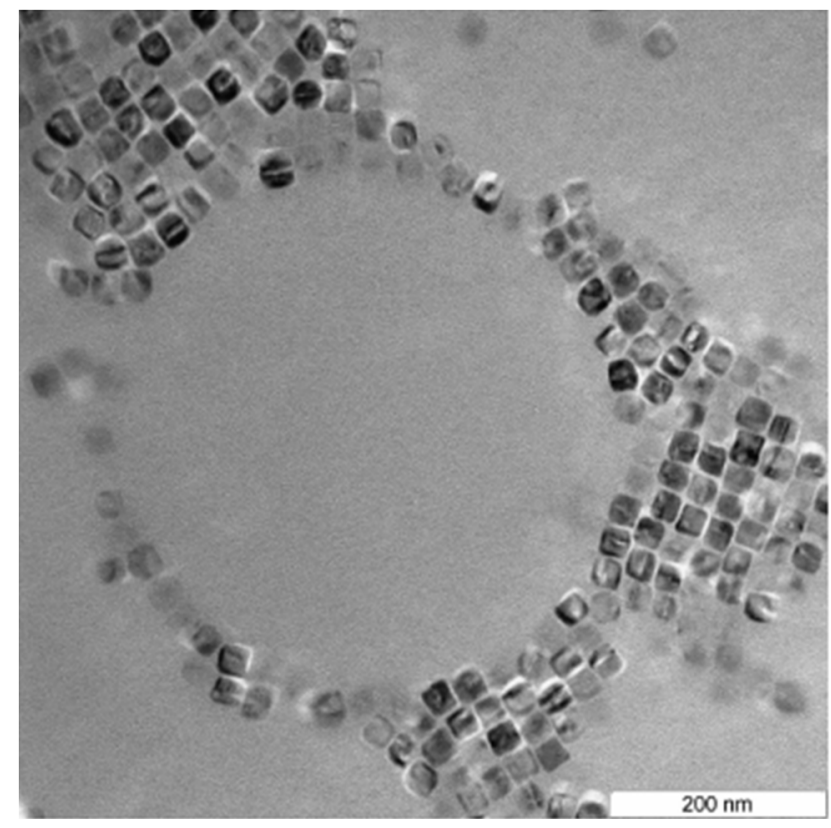

Figure 6. TEM image for the complex mixture of PIB at $150 \mathrm{ppm}$ and SDS at $1000 \mathrm{ppm}$.

\section{Conclusions}

The DR efficacy of diesel fuel was investigated individually and as complex mixture using two types of additives, namely, cationic polymer (i.e., PIB) and anionic surfactant (i.e., SDS). A high-precision RDA was used in studying the effect of several parameters, such as additive concentration, additive types, and rotational disk speed. In addition, the morphology structure of the polymer-surfactant mixture was investigated through TEM. All these solutions were determined to behave as good DRAs. The DR efficacy induced by the complex mixture is determined to be higher than that of the polymer and surfactant alone. Furthermore, the DR performance increased with increasing additive concentration and rotational disk speed in all cases. The maximum \%DR observed was $21.455 \%$ for the complex mixture at $3000 \mathrm{rpm}(R e=453,341)$.

Supplementary Materials: The following are available online at www.mdpi.com/2076-3417/6/12/355/s1, Table S1: Stander deviation and stander error for five PIB concentrations at different rotational speeds, Table S2: Stander deviation and stander error for five SDS concentrations at different rotational speeds, Table S3: Stander deviation and stander error for five complex mixture concentrations at different rotational speeds, Table S4: The effects of PIB concentrations on \%DR of diesel fuel with different rotational speeds, Table S5: The effects of rotational speed on \%DR of diesel fuel with different PIB concentrations, Table S6: The effects of SDS concentrations on \%DR of diesel fuel with different rotational speeds, Table S7: The effects of rotational speed on \%DR of diesel fuel with different SDS concentrations, Table S8: The effects of complex mixture concentrations on \%DR of diesel fuel with different rotational speeds, Table S9: The effects of rotational speed on \%DR of diesel fuel with different complex mixture concentrations.

Acknowledgments: The authors of this paper wish to express their profound gratitude to the University Putra Malaysia for funding this research work.

Author Contributions: Hayder A. Abdulbari conceived and designed the experiments; Musaab K. Rashed performed the experiments; Mohd Halim Shah Ismail and Musaab K. Rashed analyzed the data; Mohammed Amran Mohd Salleh contributed reagents/materials/analysis tools; Hayder A. Abdulbari, Mohammed Amran Mohd Salleh and Musaab K. Rashed wrote the paper.

Conflicts of Interest: The authors declare no conflict of interest. And the founding sponsors had no role in the design of the study; in the collection, analyses, or interpretation of data; in the writing of the manuscript, and in the decision to publish the result. 


\section{References}

1. Abubakar, A.; Al-Wahaibi, T.; Al-Wahaibi, Y.; Al-Hashmi, A.R.; Al-Ajmi, A. Roles of drag reducing polymers in single- and multi-phase flows. Chem. Eng. Res. Des. 2014, 92, 2153-2181. [CrossRef]

2. Choi, H.J.; Jhon, M.S. Polymer-induced turbulent drag reduction. Ind. Eng. Chem. Res. 1996, 35, $2993-2998$. [CrossRef]

3. Kim, C.A.; Jo, D.S.; Choi, H.J.; Kim, C.B.; Jhon, M.S. A high-precision rotating disk apparatus for drag reduction characterization. Polym. Test. 2000, 20, 43-48. [CrossRef]

4. Choi, H.J.; Kim, C.A.; Sung, J.H.; Kim, C.B.; Chun, W.; Jhon, M.S. Universal drag reduction characteristics of saline water-soluble poly(ethylene oxide) in a rotating disk apparatus. Colloid Polym. Sci. 2000, 278, 701-705. [CrossRef]

5. Lim, S.T.; Hong, C.H.; Choi, H.J.; Lai, P.; Chan, C.K. Polymer turbulent drag reduction near the theta point. Europhys. Lett. 2007, 80, 65-78. [CrossRef]

6. Sung, J.H.; Lim, S.T.; Kim, C.A.; Chung, H.; Choi, H.J. Mechanical degradation kinetics of poly(ethylene oxide) in a turbulent flow. Korea Aust. Rheol. J. 2004, 16, 57-62.

7. Kim, N.; Kim, S.; Hoon, S.; Chen, K.; Chun, W. Measurement of drag reduction in polymer added turbulent flow. Int. Commun. Heat Mass Transf. 2009, 36, 1014-1019. [CrossRef]

8. Yang, K.S.; Choi, H.J.; Kim, C.B.; Jhon, M.S. A study of drag reduction by polymer additives in rotating disk geometry. Korean J. Rheol. 1991, 3, 76-85.

9. Liberatore, M.W.; Baik, S.; Mchugh, A.J.; Hanratty, T.J. Turbulent drag reduction of polyacrylamide solutions: Effect of degradation on molecular weight distribution. J. Non Newton. Fluid Mech. 2004, 123, 175-183. [CrossRef]

10. Rao, T.P.; Prasad, P.R.; Sagar, K.S.; Sujatha, V. Effect of polyacrylamide on drag reduction for flow through annular conduits. Int. J. Futur. Sci. Eng. Technol. 2013, 2, 250-260.

11. Shanshool, J.; Haider, M.T. Effect of molecular weight on turbulent drag reduction with polyisobutylene. In Proceedings of the First Regional Conference of Engineering and Sceince, Mexico City, Mexico, 27-29 April 2008; pp. 52-59.

12. Mowla, D.; Naderi, A. Experimental study of drag reduction by a polymeric additive in slug two-phase flow of crude oil and air in horizontal pipes. Chem. Eng. Sci. 2006, 61, 1549-1554. [CrossRef]

13. Lee, K.; Kim, C.A.; Lim, S.T.; Kwon, D.H.; Choi, H.J.; Jhon, M.S. Mechanical degradation of polyisobutylene under turbulent flow. Colloid Polym. Sci. 2002, 280, 779-782. [CrossRef]

14. Lee, K.H.; Zhang, K.; Choi, H.J. Time dependence of turbulent drag reduction efficiency of polyisobutylene in kerosene. J. Ind. Eng. Chem. 2010, 16, 499-502. [CrossRef]

15. Escudier, M.P.; Presti, F.; Smith, S. Drag reduction in the turbulent pipe flow of polymers. J. Nonnewton. Fluid Mech. 1999, 81, 197-213. [CrossRef]

16. Tian, M.; Fang, B.; Jin, L.; Lu, Y.; Qiu, X.; Jin, H.; Li, K. Rheological and drag reduction properties of hydroxypropyl xanthan gum solutions. Chin. J. Chem. Eng. 2015. [CrossRef]

17. Wyatt, N.B.; Gunther, C.M.; Liberatore, M.W. Drag reduction effectiveness of dilute and entangled xanthan in turbulent pipe flow. J. Nonnewton. Fluid Mech. 2011, 166, 25-31. [CrossRef]

18. Hong, C.H.; Zhang, K.; Choi, H.J.; Yoon, S.M. Mechanical degradation of polysaccharide guar gum under turbulent flow. J. Ind. Eng. Chem. 2010, 16, 178-180. [CrossRef]

19. Kim, C.A.; Lim, S.T.; Choi, H.J.; Sohn, J.I.; Jhon, M.S. Characterization of drag reducing guar gum in a rotating disk flow. J. Appl. Polym. Sci. 2002, 83, 2938-2944. [CrossRef]

20. Choi, H.J.; Kim, C.A.; Sohn, J.; Jhon, M.S. An exponential decay function for polymer degradation in turbulent drag reduction. Polym. Degrad. Stab. 2000, 69, 341-346. [CrossRef]

21. Myska, J.; Mik, V. Degradation of surfactant solutions by age and by a flow singularity. Chem. Eng. Process. Process. Intensif. 2004, 43, 1495-1501. [CrossRef]

22. Li, F.; Kawaguchi, Y.; Yu, B.; Wei, J.; Hishida, K. Experimental study of drag-reduction mechanism for a dilute surfactant solution flow. Int. J. Heat Mass Transf. 2008, 51, 835-843. [CrossRef]

23. Inaba, H.; Aly, W.I.A.; Haruki, N.; Horibe, A. Flow and heat transfer characteristics of drag reducing surfactant solution in a helically coiled pipe. Heat Mass Transf. 2005, 41, 940-952. [CrossRef]

24. Mohsenipour, A.A.; Pal, R.; Prajapati, K. Effect of cationic surfactant addition on the drag reduction behaviour of anionic polymer solutions. Can. J. Chem. Eng. 2013, 91, 181-189. [CrossRef] 
25. Kwak, J.C. Polymer-Surfactant Systems; Marcel Dekker Inc.: New York, NY, USA, 1998.

26. Bakshi, M.S.; Kaur, R.; Kaur, I.; Mahajan, R.K.; Sehgal, P.; Doe, H. Unlike surfactant-polymer interactions of sodium dodecyl sulfate and sodium dodecylbenzene sulfonate with water-soluble polymers. Colloid Polym. Sci. 2003, 281, 716-726. [CrossRef]

27. Spyropoulos, F.; Ding, P.; Frith, W.J.; Norton, I.T.; Wolf, B.; Pacek, A.W. Interfacial tension in aqueous biopolymer-surfactant mixtures. J. Colloid Interface Sci. 2008, 317, 604-610. [CrossRef] [PubMed]

28. Goddard, E.D. Polymer-surfactant interaction part II. Polymer and surfactant of opposite charge. Colloids Surf. 1986, 19, 301-329. [CrossRef]

29. Wei, Y.C.; Hudson, S.M. The interaction between polyelectrolytes and surfactants of opposite charge. J. Macromol. Sci. Part C 1995, 35, 15-45. [CrossRef]

30. Matras, Z.; Kopiczak, B. Intensification of drag reduction effect by simultaneous addition of surfactant and high molecular polymer into the solvent. Chem. Eng. Res. Des. 2015, 96, 35-42. [CrossRef]

31. Matras, Z.; Malcher, T.; Gzyl-malcher, B. The influence of polymer-surfactant aggregates on drag reduction. Thin Solid Films 2008, 516, 8848-8851. [CrossRef]

32. Abdulbari, H.; Faraj, J.G.E.; Mahmood, W. Energy dissipation reduction using similarly-charged polymer-surfactant complex. Adv. Appl. Fluid Mech. 2015, 18, 113. [CrossRef]

33. Bari, H.A.; Yousif, Z.; Akindoyo, E.O. Enhancement of additives polymeric drag resistance to degradation. J. Purity Util. React. Environ. 2015, 4, 48-55.

34. Kim, J.T.; Kim, C.A.; Zhang, K.; Jang, C.H.; Choi, H.J. Effect of polymer-surfactant interaction on its turbulent drag reduction. Colloids Surf. A Physicochem. Eng. Asp. 2011, 391, 125-129. [CrossRef]

35. Bari, H.A.; Faraj, E. Studying the interaction between a new mixture in enhancing drag reduction efficiency. Int. J. Chem. Eng. Appl. 2015, 6, 277-280.

36. Sohn, J.I.; Kim, C.A.; Choi, H.J.; Jhon, M.S. Drag-reduction effectiveness of xanthan gum in a rotating disk apparatus. Carbohydr. Polym. 2001, 45, 61-68. [CrossRef]

37. Sung, J.H.; Kim, C.A.; Choi, H.J.; Hur, B.K.; Kim, J.G.; Jhon, M.S. Turbulent drag reduction efficiency and mechanical degradation of poly (acrylamide). J. Macromol. Sci. Part B 2004, 43, 507-518. [CrossRef]

38. Akindoyo, E.O.; Abdulbari, H.A.; Yousif, Z. A dual mechanism of the drag reduction by rigid polymers and cationic surfactant: Complex and nanofluids of xanthan gum and hexadecyl trimethyl ammonium chloride. Int. J. Res. Eng. Technol. 2015, 4, 84-93.

39. Held, P. Rapid Critical Micelle Concentration (CMC) Determination Using Fluorescence Polarization. Available online: http://www.biotek.com/resources/articles/cmc_determination_using_fluorescence_ polarization.html (accessed on 18 September 2014).

40. Bari, H.A.A.; Yousif, Z.; Yaacob, Z.B.; Oluwasogaakindoyo, E. Effect of SDBS on the drag reduction characteristics of polyacrylamide in a rotating disk apparatus. Int. J. Basic Appl. Sci. 2015, 4, 326-332. [CrossRef]

(C) 2016 by the authors; licensee MDPI, Basel, Switzerland. This article is an open access article distributed under the terms and conditions of the Creative Commons Attribution (CC-BY) license (http:/ / creativecommons.org/licenses/by/4.0/). 